\title{
Determination of the Chemical Stability of Cyanocobalamin in Medical Food by a Validated Immunoaffinity Column-Linked HPLC Method
}

\author{
Wonjong Lee, Yoon-Bok Lee, Moon Haeng Huh, and Jae Kwon Choi \\ Central Research Institute, Dr. Chung's Food Co. Ltd, 124 Sandan-Ro, Heungdeok-Gu, Cheongju 28446, Republic of Korea \\ Correspondence should be addressed to Jae Kwon Choi; cjk038@vegemil.co.kr
}

Received 31 August 2021; Accepted 31 December 2021; Published 12 January 2022

Academic Editor: Muhammad Faisal Manzoor

Copyright (C) 2022 Wonjong Lee et al. This is an open access article distributed under the Creative Commons Attribution License, which permits unrestricted use, distribution, and reproduction in any medium, provided the original work is properly cited.

\begin{abstract}
Cyanocobalamin, which plays an essential role in the body, is a synthetic form used in medical food. This present study aimed to develop an HPLC analysis method for determination cyanocobalamin and investigate the stability of cyanocobalamin in medical food. Validation of the developed method for cyanocobalamin was evaluated with linearity, LOD, LOQ, and accuracy. The linearity of this method was calculated with a value of the coefficient of determination $\left(R^{2}\right) \geq 0.999$. LOD and LOQ were 0.165 and $0.499 \mu \mathrm{g} / \mathrm{kg}$, respectively. The recovery of medical food matrixes for accuracy was more than $97.63 \%$. The validated method was applied for determining cyanocobalamin from medical foods. The developed method was used to examine the additives for cyanocobalamin protection. Ferric chloride and sorbitol alleviated cyanocobalamin degradation from heat and ascorbic acid. Especially, sorbitol showed a superior protective effect during the medical food production process. Therefore, this study suggests that sorbitol is a sweetener additive that prevents cyanocobalamin degradation by heat and the food matrix in medical food processing.
\end{abstract}

\section{Introduction}

Cobalamin, also known as vitamin $\mathrm{B}_{12}$, is a water-soluble micronutrient that is one of the $\mathrm{B}$ group vitamins and has a cobalt-centered corrin ring in its molecular structure [1]. It plays a pivotal role in the production of DNA, blood cells, and the repair of neurological functions [2]. Cobalamin has several bioactive forms and many analogues by differences in their upper axial ligand such as hydroxocobalamin, cyanocobalamin, and methylcobalamin [3]. Among these cobalamins, cyanocobalamin is mainly used in fortified foods and supplements for humans and animals because it is the most stable analogue compared with other cobalamins $[3,4]$.

Foods fortified with cyanocobalamin are required to be monitored for quality control, product development, and compliance purposes including nutrition labelling. The quantitative analysis of cyanocobalamin, which is added in microamounts to medical foods, is difficult and requires an excellent detection limit, owing to the diversity of medical food matrixes and interactions of multinutrient interactions during production processes and storage $[5,6]$. Several studies have been reported that focus on the quantitative aspects of cyanocobalamin in different matrices. Available methods for cobalamin analysis in various matrices include polargraphic, spectrophotometric, and various chromatographic procedures including open-column, thin-layer, and liquid chromatography procedures [7-10]. However, previous research lacks studies for the determination of cyanocobalamin in complex food matrices such as medical foods. Besides, those studies are focused on total cobalamin contents rather than contents of only cyanocobalamin, which needs to be confirmed for product development and quality guarantee [8-10].

Because medical food is generally consumed by patients who require use of the product as a major component of dietary management specific to a condition or disease, it is essential to have a sterilization process in the medical food production process $[11,12]$. When exposed to heat, cyanocobalamin in aqueous solution undergoes degradation that is temperature and time dependent [13, 14]. Berry 
Ottaway reported that cyanocobalamin is unstable in conditions for sterilization of milk [15]. These studies indicate that cyanocobalamin can be easily destroyed by high temperatures. Moreover, medical food contains various nutrients such as vitamins and minerals for balanced nutrition of patients [11]. Although sterilization and various nutrients are needed for medical food, they influence the stability of cyanocobalamin that is contained in the medical food [16]. Ahmad et al. confirmed that cyanocobalamin is degraded in the presence of ascorbic acid, nicotinamide, and thiamine by promotion of the photodegradation. The chemical degradation of cyanocobalamin resulted in cleavage of the corrin ring nucleus of the vitamin [2]. In medical foods, cyanocobalamin is a crucial nutrient for the dietary management of disease and nutritional requirements [17]. Therefore, the stability of cyanocobalamin in medical foods of liquid form can be affected by heat treatment and interactions between various nutrients during the production process and storage [13-16]. However, the stability of cyanocobalamin in medical foods has not been studied.

The purpose of this research was to validate an analytical method that has improved sensitivity for the determination cyanocobalamin in medical food matrix by using a highperformance liquid chromatography (HPLC) technique. Also the research offers important insights into the thermal and interactional stability of cyanocobalamin in medical food processing.

\section{Materials and Methods}

2.1. Chemicals and Reagents. Chemicals such as cyanocobalamin standard, ascorbic acid, and potassium phosphate were obtained from Sigma-Aldrich (St. Louis, MO, USA). Methanol (HPLC grade solvent) was purchased from Merck (Frankfurter, Germany).

2.2. Instruments. HPLC (Agilent Technologies, Santa Clara, CA) equipped with an autosampler, pump, diode array detector (DAD), and valve system was used. Other equipment included a sonicator (Branson 3500, Connecticut, USA), centrifuge (Hanil, Gimpo, Korea), and spectrophotometer (Molecular Devices, Pharmacia, USA).

2.3. Preparation of the Sample. Cyanocobalamin-fortified medical food products were provided by Dr. Chung's Food Co. Ltd. (Cheongju, Korea). We added sorbitol $(0.25 \%$, w/v) to the medical food products to examine changes in cyanocobalamin contents in the matrices during thermal treatments. The final samples were obtained after two-step sterilization at $135^{\circ} \mathrm{C}$ for $72 \mathrm{sec}$ and at $124^{\circ} \mathrm{C}$ for $10 \mathrm{~min}$, according to the medical food manufacturing processes of Dr. Chung's Food Co. Ltd.

2.4. Extraction and Enrichment of Cyanocobalamin on an Immunoaffinity Column. Each sample was suspended in $0.2 \mathrm{M}$ sodium acetate solution $(\mathrm{pH} 4.0)$ and extracted by sonication for $30 \mathrm{~min}$. After sonication, we filtered the extract through filter paper (Whatman No. 2, GE Healthcare, Amersham Place, UK), and the clear layer was purified through an immunoaffinity column (IAC) step.

We performed extraction of cyanocobalamin for validation analysis according to the recommendations of the IAC manufacturer, with minor adaptations, as follows. The IAC stored in the refrigerator was allowed to stand at room temperature for $30 \mathrm{~min}$, and then, the buffer solution inside the column was completely removed. The column was activated with $3 \mathrm{~mL}$ of water followed by $9 \mathrm{~mL}$ of the extraction of cyanocobalamin. After the cyanocobalamin extraction passed, the IAC was washed with $3 \mathrm{~mL}$ of water 3 times repeatedly. The cyanocobalamin was eluted by passing $6 \mathrm{~mL}$ of methanol under gravity. The extracts were collected in a $15 \mathrm{~mL}$ amber vial and dried under a stream of $\mathrm{N}_{2} .1 \mathrm{~mm}$ of $5 \mathrm{mM}$ potassium phosphate solution was added to the tube and then filtered with a $0.22 \mu \mathrm{m}$ filter membrane for chromatography analysis.

2.5. Column-Switching HPLC System. A column-switching system in backflush configuration was adopted for the analysis of cyanocobalamin in medical foods. The functional principle of the two-column assembly is described in more detail in Table 1 . The analyses were performed at $40^{\circ} \mathrm{C}$ and with the DAD operating at $361 \mathrm{~nm}$. Pump A delivers mobile phase 1 composed by $\mathrm{MeOH}: 5 \mathrm{mM} \mathrm{KH}_{2} \mathrm{PO}_{4}$ solution (15: $85, \mathrm{v} / \mathrm{v}$ ) through the preseparation column at a constant flow rate of $0.3 \mathrm{~mL} / \mathrm{min}$. Pump $\mathrm{A}$ was connected to a manual injector equipped with a loop of $500 \mu \mathrm{L}$. Pump B delivers mobile phase 2 (MeOH:5 mM KH${ }_{2} \mathrm{PO}_{4}$ solution $(25: 75$, v/ $\mathrm{v})$ ) at a constant flow rate of $0.3 \mathrm{~mL} / \mathrm{min}$.

2.6. Validation of the Method. The proposed method was validated in accordance with the Association of Official Analytical Chemists (AOAC) guideline and International Conference of Harmonisation (ICH) guideline $[18,19]$ for various parameters such as specificity, linearity, detection and quantification limit, accuracy, and precision.

The linearity of cyanocobalamin analysis was tested at ten different concentrations of cyanocobalamin standard solution $(0.167,0.318,0.588,1.267,3.398,6.037,12.734$, $27.519,56.497$, and $113.955 \mu \mathrm{g} / \mathrm{kg}$ ). The limit of quantification (LOQ) and limit of detection (LOD) were calculated from the relationship between the slope of the regression line and standard deviation (SD) of the response at low concentrations of cyanocobalamin $(\mathrm{LOD}=3.3 \times \sigma /$ slope and LOQ $=10 \times \sigma /$ slope, where $\sigma=$ the SD of the response) [19]. Accuracy of the cyanocobalamin assay was investigated by analyzing a certified reference material (SRM1849a (infant/ adult nutrition formula); NIST, MD, USA) and comparing the analytical values with the corresponding certified values. In addition, we evaluated the accuracy and precision by spiking cyanocobalamin standard in medical food without cyanocobalamin (Dr. Chung's Food Co., Ltd., Cheongju, Korea).

Furthermore, participation in a proficiency test (Test 21119) from the Food Analysis Performance Assessment 
TABLE 1: HPLC analysis condition for cyanocobalamin analysis.

\begin{tabular}{lc}
\hline Parameters & Conditions \\
\hline Column & $\begin{array}{c}\text { Agilent Poroshell BONUS RP }(4.6 \mathrm{~mm} \times 150 \mathrm{~mm}, 2.7 \mu \mathrm{m}) \\
\text { Agilent Poroshell EC-C18 }(4.6 \mathrm{~mm} \times 50 \mathrm{~mm}, 2.7 \mu \mathrm{m})\end{array}$ \\
Agilent Poroshell SB-AQ $(4.6 \mathrm{~mm} \times 150 \mathrm{~mm}, 2.7 \mu \mathrm{m})$
\end{tabular}

Scheme (FAPAS) was also conducted to further assess the reliability and accuracy of the validated analytical method.

2.7. Detection of Thermal Stability of Cyanocobalamin. To assess the impact of heat on the stability of cyanocobalamin, we used to cyanocobalamin standard solution $(100 \mathrm{mg} / \mathrm{kg})$ and sterilized medical food products. The cyanocobalamin standard solutions were placed in a $124^{\circ} \mathrm{C}$ drying oven (JISICO Co., Korea) for $10 \mathrm{~min}$. The medical food products were sterilized by manufacturing processes of Dr. Chung's Food Co., Ltd. After being placed in a drying oven or sterilization in medical food, the samples were analyzed for cyanocobalamin by the abovementioned HPLC analysis method.

Food additives including ascorbic acid $(1,5,10,20,50$, and $100 \mathrm{mg} / \mathrm{kg}$ ), ferric chloride $(1 \mathrm{mM})$, and sorbitol $(0.25 \%$, $\mathrm{w} / \mathrm{v}$ ) were added to confirm interactions between cyanocobalamin and the additives.

2.8. Statistical Analysis. The values for statistical analysis were expressed as the means \pm SD and performed with SPSS software (version 23; SPSS/IBM). Statistical comparisons between the various groups were carried out by analysis of variance (ANOVA) followed by Tukey's post hoc test for three-group comparisons using SPSS software.

\section{Results and Discussion}

3.1. Development of the Chromatographic Method. The stability of cyanocobalamin is reduced by heat, UV light, $\mathrm{pH}$, and interaction with other water-soluble vitamins [16]. Previous studies used sodium cyanide and sodium acetate buffers in an extraction step to confirm all cobalamins including degraded cobalamin [6]. The addition of sodium cyanide could detect all cobalamins in test samples through degraded cobalamin converted to cyanocobalamin. However, because the previous method focuses on identifying cobalamins in foods, it is not possible to assess the residual cyanocobalamin content in food products. Therefore, this study was focused on identification of cyanocobalamin remaining in a finished product by removing the addition of sodium cyanide during the extraction of cyanocobalamin.

We also presented a novel measurement wavelength of cyanocobalamin different from the $550 \mathrm{~nm}$ in previous studies.
The DAD spectrum for the cyanocobalamin peak of the standard indicated that $361 \mathrm{~nm}$ has much better sensitivity than $550 \mathrm{~nm}$ (Figure 1(a)). Although the UV spectrum for cyanocobalamin has a maximum peak at $361 \mathrm{~nm}$, it has been reported that peak separation at $361 \mathrm{~nm}$ is very difficult because of matrix interferences [6, 7]. Other vitamins, organic acids, and amino acids, as well as cobalamins, absorb in the UV region. Riboflavin, thiamine, ascorbic acid, pyridoxine, nicotinamide, tyrosine, folic acid, tryptophan, and phenylalanine have absorbance at $260 \mathrm{~nm}$, and several compounds, including folic acid and riboflavin, have absorbance at $360 \mathrm{~nm}$ $[6,7]$. For these reasons, previous studies suggested that monitoring at $550 \mathrm{~nm}$ was adequate for cyanocobalamin determination, even though $361 \mathrm{~nm}$ has much better sensitivity than $550 \mathrm{~nm}$ [7]. However, we could observe cyanocobalamin at the maximum absorbance of $361 \mathrm{~nm}$ because the medical foods or pretreatment samples were decanted without matrix interferences because of the cyanocobalamin-specific IAC clean-up step. As a result, the sensitivity of cyanocobalamin was improved compared with the peak of $550 \mathrm{~nm}$ (Figure 1(b)). Also, this was applied on the expectation that it would have an effect on the LOQ and LOD as well.

\subsection{Method Validation of the Immunoaffinity Column-Linked} Column-Switching HPLC/DAD. The optimized chromatographic conditions were applied to validation for linearity, sensitivity, and accuracy. The linearity of the analytical method was confirmed to be a proportional relationship between the analyzed concentration and peak area. The linearity was evaluated at ten concentration levels in the concentration range $0.167-114 \mu \mathrm{g} / \mathrm{kg}$ in real samples, and each concentration level was calculated. The correlation coefficient $R^{2}>0.999$ of the regression line (Table 2) indicates an excellent linear correlation between the cyanocobalamin concentration and peak area in the studied concentration range. The LOD for cyanocobalamin was $0.165 \mu \mathrm{g} / \mathrm{kg}$, and the LOQ was $0.499 \mu \mathrm{g} / \mathrm{kg}$. These results are an improvement compared with previous studies [6,7], and this improvement is attributed to the change in wavelength to $361 \mathrm{~nm}$.

The accuracy and precision of this analysis for cyanocobalamin was examined in an infant formula and medical food matrix (Table 3 ). The analyzed cyanocobalamin contents of SRM1849a by the developed method was $0.0465 \mu \mathrm{g} / \mathrm{kg}$, resulting in $94.42 \%$ recovery. Liquid medical food without 

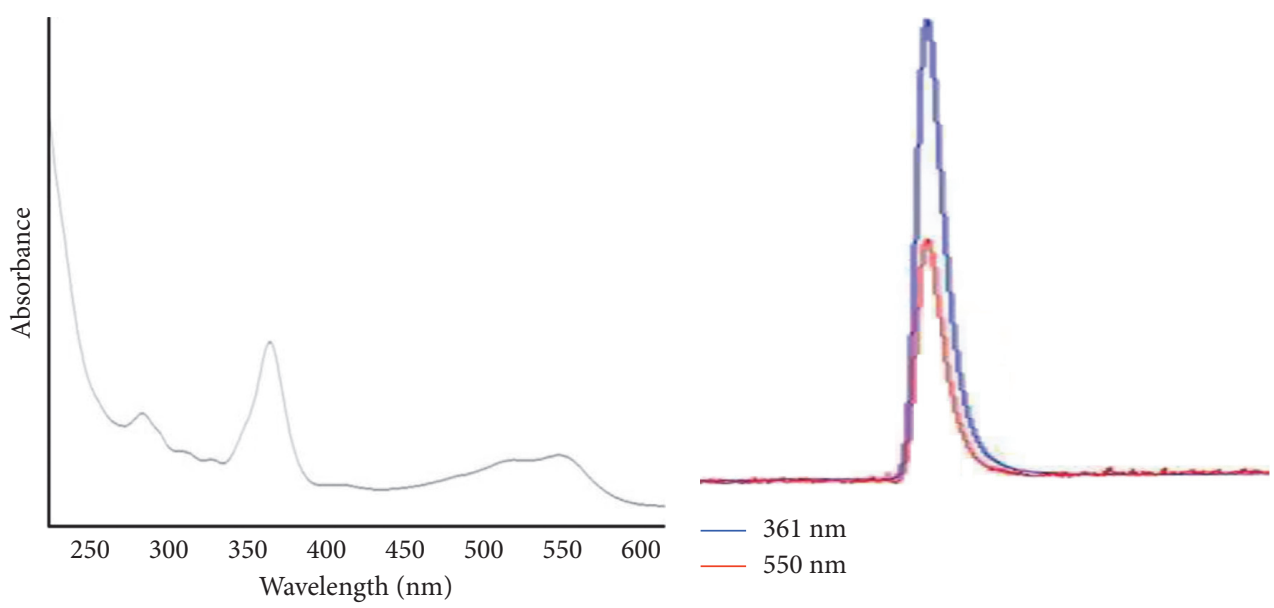

(a)

(b)

FIGURE 1: Sensitivity of cyanocobalamin: (a) absorption spectra of cyanocobalamin solution; (b) comparison of sensitivity on wavelength 361 and $550 \mathrm{~nm}$ through HPLC chromatogram.

TABLE 2: Calibration curves, LOD, and LOQ of HPLC analysis for cyanocobalamin.

\begin{tabular}{lcccc}
\hline Compound & Calibration curve & $R^{2}$ & LOD $(\mu g / k g)$ & LOQ $(\mu g / k g)$ \\
\hline Cyanocobalamin & $y=2.6111 x+8.5503$ & 0.9999 & 0.165 & 0.499 \\
\hline
\end{tabular}

TABLE 3: Accuracy and precision of HPLC analysis for cyanocobalamin.

\begin{tabular}{|c|c|c|c|c|c|c|}
\hline \multirow[b]{2}{*}{ Compound } & \multirow[b]{2}{*}{ Standard added $(\mathrm{mg} / \mathrm{kg})$} & \multicolumn{3}{|c|}{ Accuracy $(n=4)$} & \multicolumn{2}{|c|}{ Precision $(n=6)$} \\
\hline & & Mean (mg/kg) & Recovery (\%) & RSD (\%) & $\begin{array}{l}\text { Intraday } \\
\text { RSD (\%) }\end{array}$ & $\begin{array}{l}\text { Interday } \\
\text { RSD (\%) }\end{array}$ \\
\hline SRM1849a & 0.0482 & $0.0465 \pm 0.0010$ & 96.42 & 2.12 & - & - \\
\hline Medical food & 0.0480 & $0.0469 \pm 0.0010$ & 97.63 & 2.09 & 3.09 & 3.26 \\
\hline
\end{tabular}

cyanocobalamin was spiked with cyanocobalamin standard compound and analyzed using the proposed method. The percentage recovery for the medical food was found to be 97.63\%. Precision including repeatability and reproducibility was evaluated by calculation of \%RSDs from repeated cyanocobalamin analysis on the same day and different days, respectively. As shown in Table 3, 3.09 and 3.26\%RSD were observed for repeatability and reproducibility, respectively. Furthermore, proficiency of the immunoaffinity-HPLC assay was evaluated by participating in the FAPAS Proficiency Test 21119 to evaluate further the validated method. When a $z$ score falls within a range of \pm 2 in the FAPAS proficiency test, it is considered fit-for-purpose [20]. With this method, the laboratory generated a $z$-score of -1.9 (data not shown), indicating that the proposed method was performed proficiently and verifying the method accuracy. Taken together, these demonstrate that the immunoaffinity-HPLC/DAD procedure applied for this analysis for cyanocobalamin is of sufficient accuracy and precision to provide consistent analytical results in medical food.

3.3. Effect of Heat on Cyanocobalamin Content in Medical Foods. As medical food is generally consumed by patients with weak immunity, it is essential to have a sterilization process in the food production process [11, 12]. Although sterilization is needed for medical food, it affects the stability of cyanocobalamin that is contained in medical food [16]. Prior to making medical food, we collected samples of commercial medical food before and after sterilization to determine whether the sterilization conditions affected cyanocobalamin content (Figure 2). The first sterilization $\left(135^{\circ} \mathrm{C}, 72 \mathrm{~s}\right)$ had a slight effect on reducing the cyanocobalamin concentration, which declined from 89.39 to $52.48 \mu \mathrm{g} / \mathrm{kg}$ in the medical food. However, cyanocobalamin was unstable and decreased to $14.63 \mu \mathrm{g} / \mathrm{kg}$ during the second sterilization at $124^{\circ} \mathrm{C}$ for $10 \mathrm{~min}$. This shows that hightemperature treatment induces degradation of cyanocobalamin and also that the developed cyanocobalamin analysis method can present the amount of cyanocobalamin maintained. Therefore, we investigated the thermal and interactional stability of cyanocobalamin in medical food processing using the developed HPLC method.

3.4. Effect of Ascorbic Acid on Heat-Induced Degradation of Cyanocobalamin. Our results showed that ascorbic acid induced dose-dependent destruction of cyanocobalamin standard solution (Figure 3). Heat treatment only decreased cyanocobalamin content to $77.46 \%$, but the reduction 


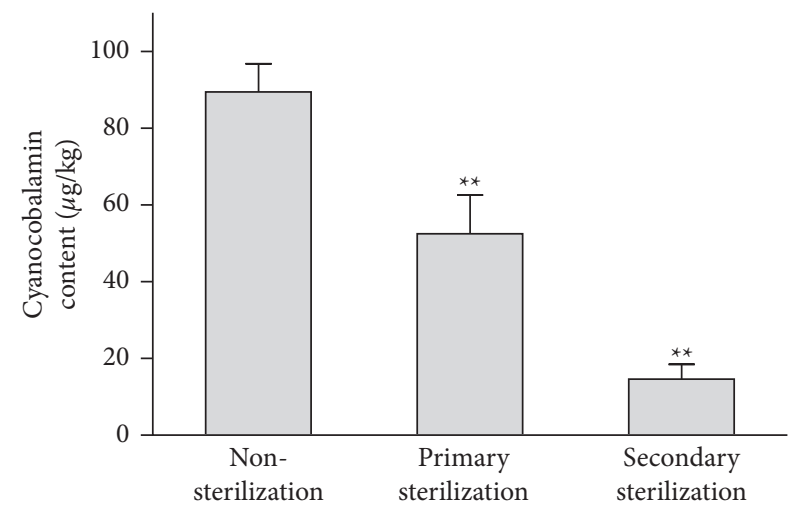

Figure 2: Cyanocobalamin content by the production process in medical food. The medical food was sterilized twice (primary sterilization, $135^{\circ} \mathrm{C}, 72 \mathrm{~s}$; secondary sterilization, $124^{\circ} \mathrm{C}, 10 \mathrm{~min}$ ) ( ${ }^{*} p<0.05$ and ${ }^{* *} p<0.01$ versus the nonsterilized sample; one-way ANOVA followed by Tukey's post hoc test).

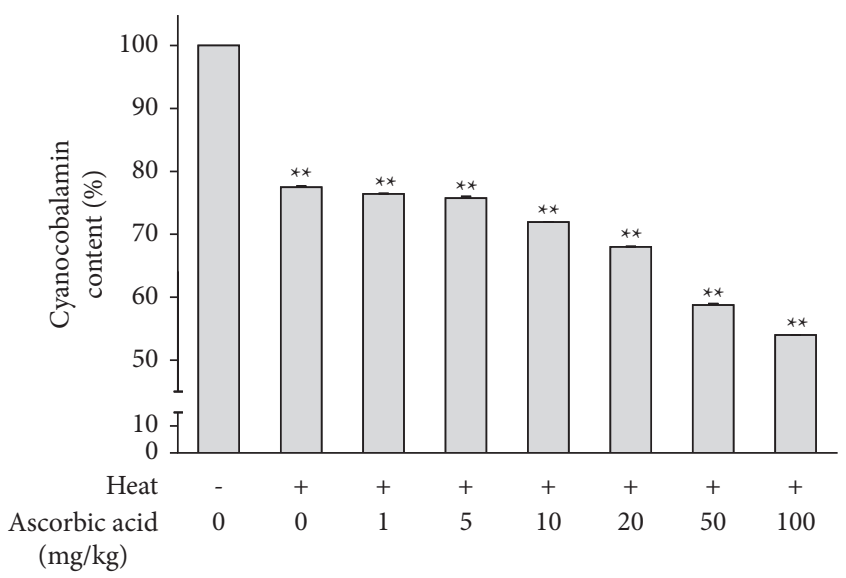

Figure 3: Effect of ascorbic acid on thermal stability of cyanocobalamin. Ascorbic acid was treated in various concentrations $(0$, $1,5,10,20,50$, and $100 \mathrm{mg} / \mathrm{kg}$ ) on heat condition $\left(124^{\circ} \mathrm{C}, 10 \mathrm{~min}\right)$ in $100 \mathrm{mg} / \mathrm{kg}$ cyanocobalamin standard solution. After heating, cyanocobalamin in the samples was measured by HPLC analysis $\left({ }^{*} p<0.05\right.$ and ${ }^{* *} p<0.01$ versus the untreated sample; one-way ANOVA followed by Tukey's post hoc test).

became greater with increased concentration of ascorbic acid. With $100 \mathrm{mg} / \mathrm{kg}$ of ascorbic acid, there was a reduction of cyanocobalamin content to $53.97 \%$ compared with nontreated cyanocobalamin solution. Previous studies reported that cyanocobalamin degraded in the presence of ascorbic acid because of first-order kinetics. Ascorbic acid reduces $\mathrm{Co}^{3+}$ to $\mathrm{Co}^{2+}$ in the corrin ring, followed by oxidation to $\mathrm{B}_{12 \mathrm{~b}}$ or the ring cleavage products in the degradation of cyanocobalamin [2, 21]. Overall, our results revealed that cyanocobalamin degradation losses caused by a combination of heat and ascorbic acid treatment occurred slightly faster than degradation losses caused by heat or ascorbic acid treatment alone. These results indicate that nutrient contents including cyanocobalamin and ascorbic acid could be reduced to less than the initially designed content in medical foods. Although ascorbic acid enhanced heat-induced degradation of cyanocobalamin, it is an essential micronutrient that cannot be excluded because it plays an important role in numerous physiological processes as an enzymatic cofactor, such as collagen synthesis and osteoblast genesis in the human body $[22,23]$. Therefore, it might be necessary to have additives for mitigating such degradation instead of excluding ascorbic acid from medical food.

\subsection{Effect of Additives on the Degradation of Cyanocobalamin.} This study next examined additives that could reduce the combined effect of heat and ascorbic acid on cyanocobalamin. Functional foods including medical foods have various additives such as nutrients, nutritive sweeteners, and flavoring agents [24]. Because ionic nutrients are essential ingredients in medical food, we first focused on minerals. Among various minerals, several minerals including ferric chloride play a role as oxidizing agents, in contrast with ascorbic acid, which is a reducing agent $[25,26]$. As shown Figure 4(a), ferric chloride addition alleviated the degradation of cyanocobalamin by the combination of heat and ascorbic acid in cyanocobalamin standard solution. The cyanocobalamin contents after heat and combination of heat/ascorbic acid treatment were $24.68 \%$ and $56.52 \%$, respectively, compared with the untreated sample. When ferric chloride was added, degradation with the combination of heat/ascorbic acid was reduced to $7.79 \%$. Ascorbic acid oxidizes dehydroascorbic acid through a variety of oxidation reactions employing ferric chloride [27]. We expected that this is likely because of the oxidizing ability of ferric chloride against ascorbic acid. Taken together, our results support the conclusion that ferric chloride as an additive of medical food protects against the degradation of cyanocobalamin by overcoming the reducing ability of ascorbic acid. However, the FDA provides reference daily intakes (RDIs) for chlorine $(2300 \mathrm{mg})$ and iron $(18 \mathrm{mg})$ [28]. Therefore, we suggest that attention needs to be paid to the input amount of ferric chloride used for increasing the stability of cyanocobalamin when producing medical food.

Nutritive sweeteners commonly found in beverages and foods contain sucrose, fructose, and glucose. Some other sweeteners with lower energy levels such as xylitol, maltose, maltodextrin, and stevia have been used [29]. Sorbitol, a well-known polyol sweetener, has glycemic regulation properties [30]. Recently, it is regarded as a preferable substitute to high-fructose corn syrup and sucrose that improves preservation effects in the production of dried fruit products $[16,31]$. Barr et al. confirmed that sucrose and dextrose cause a reduction in cyanocobalamin content [14]. Sorbitol, on the other hand, was compatible in cobalamin aqueous solution at high temperatures, which decreases the amount of available water that promotes cobalamin hydrolysis $[14,16]$. In this study, samples with added sorbitol that were treated at $124^{\circ} \mathrm{C}$ for $10 \mathrm{~min}$ showed a $47.72 \%$ increase in cyanocobalamin compared with heat-/ascorbic acid-treated samples (Figure 4(b)). This supports previous findings that degradation of cyanocobalamin is reduced by sorbitol that binds to available water and slows down the rate of hydrolysis [14, 16]. Taken together, the addition of 


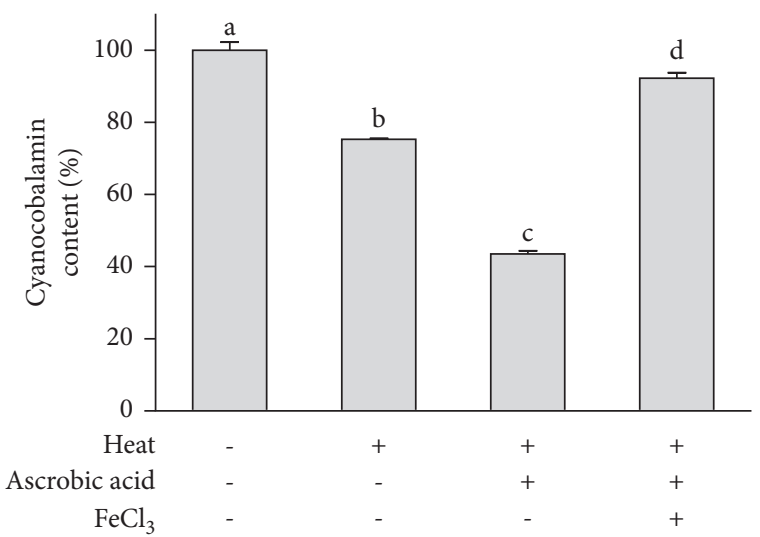

(a)

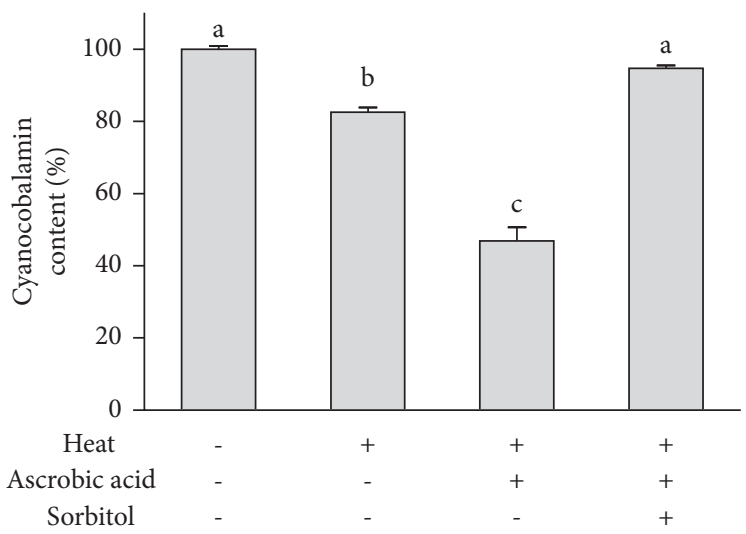

(b)

FIGURE 4: Effects of micronutrient and sugar alcohol on the degradation of cyanocobalamin against the combination effect between heat $\left(124^{\circ} \mathrm{C}, 10 \mathrm{~min}\right)$ and ascorbic acid $(100 \mathrm{mg} / \mathrm{kg})$ treatment: (a) ferric chloride $(1 \mathrm{mM})$ or (b) sorbitol $(0.25 \%$, w/v) was treated in $100 \mathrm{mg} / \mathrm{kg}$ cyanocobalamin standard solution and heated at $124^{\circ} \mathrm{C}$ for $10 \mathrm{~min}$. After heating, cyanocobalamin in the samples was measured by HPLC analysis. Values with different letters ( $\mathrm{a}-\mathrm{d}$ ) are significantly different at $p<0.01$ by post hoc Tukey's test.

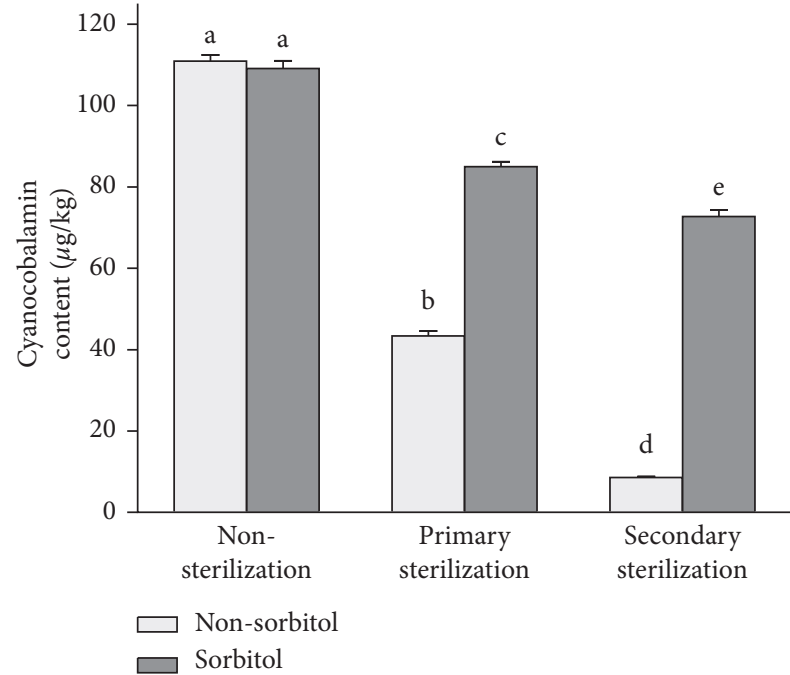

Figure 5: Cyanocobalamin content by the production process in commercial and modified medical foods. The medical foods had a matrix containing ascorbic acid and were sterilized twice (primary sterilization, $135^{\circ} \mathrm{C}, 72 \mathrm{~s}$; secondary sterilization, $124^{\circ} \mathrm{C}, 10 \mathrm{~min}$ ). The modified medical food was added $0.25 \%(\mathrm{w} / \mathrm{v})$ sorbitol. Values with different letters (a-e) are significantly different at $p<0.01$ by post hoc Tukey's test.

sorbitol to heat-treated samples appears to be effective for reducing cyanocobalamin degradation loss, indicating the sorbitol could have a preventive effect for cyanocobalamin reduction.

3.6. Cyanocobalamin Protective Effect of Sorbitol in Product Processing of Medical Food. Finally, this study examined the stability of cyanocobalamin in product processing of medical food. We produced normal medical food and the medical food with added sorbitol. As shown Figure 5, the normal medical food without sorbitol was observed to degrade cyanocobalamin during the production process. On the other hand, the samples with added sorbitol had significantly $(p<0.01)$ higher cyanocobalamin than those without the added sugar alcohols. When sorbitol was added, cyanocobalamin was $84.95 \mu \mathrm{g} / \mathrm{kg}$ compared with $43.34 \mu \mathrm{g} / \mathrm{kg}$ for the sample without sorbitol at primary sterilization. Even after secondary sterilization, cyanocobalamin was higher $(64.16 \%)$ in the samples with added sorbitol $(72.73 \mu \mathrm{g} / \mathrm{kg})$ than those without sorbitol $(8.57 \mu \mathrm{g} / \mathrm{kg})$. These results indicate that sorbitol may have a sufficient protective effect on cyanocobalamin in product processing of commercial medical food. Taking these results together, we suggest that sorbitol is a superior cyanocobalamin-protective additive in diabetes medical food because sorbitol has an antihyperglycemic effect as well as a protective effect of cyanocobalamin.

\section{Conclusions}

This study developed an HPLC analysis method for the determination of cyanocobalamin and investigated the stability of cyanocobalamin in medical food. We validated the cyanocobalamin analysis method for determining which compounds are contained in trace amounts. The developed method was used to examine for additives for cyanocobalamin protection. Although ferric chloride and sorbitol had protective effects of cyanocobalamin degradation in this study, ferric chloride was inappropriate because there is a need to pay attention to RDIs and the destruction of ascorbic acid. On the other hand, sorbitol was the superior protective additive as well as an antihyperglycemic sweetener in a diet for insulin-dependent diabetes. Therefore, this study suggests that sorbitol is a sweetener additive that protects against cyanocobalamin degradation caused by heat and the food matrix in medical food processing.

\section{Abbreviations}

DAD: Diode array detector 
IAC: Immunoaffinity column

AOAC: Association of official analytical chemists

ICH: International conference of harmonisation

LOD: Limit of detection

LOQ: Limit of quantification

SD: $\quad$ Standard deviation

FAPAS: Food analysis performance assessment scheme

RDIs: Reference daily intakes.

\section{Data Availability}

The data that support the finding of this study are available from the corresponding author upon reasonable request.

\section{Conflicts of Interest}

The authors declare no conflicts of interest regarding the publication of this article.

\section{Acknowledgments}

The authors acknowledge Dr. Chung's Food Co., Ltd., for providing the medical foods.

\section{References}

[1] S. Bodur, S. Erarpat, U. Balçık, and S. Bakırdere, "A rapid, sensitive and accurate determination of cobalamin with double monitoring system: HPLC-UV and HPLC-ICP-OES," Food Chemistry, vol. 340, Article ID 127945, 2021.

[2] I. Ahmad, K. Qadeer, S. Zahid et al., "Effect of ascorbic acid on the degradation of cyanocobalamin and hydroxocobalamin in aqueous solution: a kinetic study," AAPS PharmSciTech, vol. 15, no. 5, pp. 1324-1333, 2014.

[3] H. Wang, Y. Shou, X. Zhu et al., "Stability of vitamin $B_{12}$ with the protection of whey proteins and their effects on the gut microbiome," Food Chemistry, vol. 276, pp. 298-306, 2019.

[4] B.-G. Jeong, G. Mun, J. Jung, and J. Chun, "ImmunoaffinityHPLC analysis for vitamin $\mathrm{B}_{12}$ of Korean cattle-hanwoo (Bos taurus coreanae)," Food Analytical Methods, vol. 11, no. 9, pp. 2597-2606, 2018.

[5] K. Yamada, M. Shimodaira, S. Chida et al., "Degradation of vitamin $\mathrm{B}_{12}$ in dietary supplements," International Journal for Vitamin and Nutrition Research, vol. 78, no. 45, pp. 195-203, 2008.

[6] B.-Y. Oh, M.-J. Ye, S.-J. Hu, H.-Y. Lee, and S.-J. Bang, "Determination of vitamin $\mathrm{B}_{12}$ and biotin in foods for special dietary uses with immunoaffinity column," Journal of Food Hygiene and Safety, vol. 35, no. 3, pp. 252-260, 2020.

[7] Y.-J. Park, J.-H. Jang, H.-K. Park, Y.-E. Koo, I.-K. Hwang, and D.-B. Kim, "Determination of vitamin $\mathrm{B}_{12}$ (cyanocobalamin) in fortified foods by HPLC," Preventive Nutrition and Food Science, vol. 8, no. 4, pp. 301-305, 2003.

[8] X. Qiu, H. Zhang, Y. Yin et al., "Determination of active vitamin $\mathrm{B}_{12}$ (cobalamin) in dietary supplements and ingredients by reversed-phase liquid chromatography: single-laboratory validation," Food Chemistry, vol. 298, Article ID 125010, 2019.

[9] E. Campos-Gimnez, P. Fontannaz, M.-J. Trisconi, T. Kilinc, C. Gimenez, and P. Andrieux, "Determination of vitamin $\mathrm{B}_{12}$ in food products by liquid chromatography/UV detection with immunoaffinity extraction: single-laboratory validation,"
Journal of AOAC International, vol. 91, no. 4, pp. 786-793, 2008.

[10] D. Guggisberg, M. C. Risse, and R. Hadorn, "Determination of vitamin $B_{12}$ in meat products by RP-HPLC after enrichment and purification on an immunoaffinity column," Meat Science, vol. 90, no. 2, pp. 279-283, 2012.

[11] N. P. Aditya, Y. G. Espinosa, and I. T. Norton, "Encapsulation systems for the delivery of hydrophilic nutraceuticals: food application," Biotechnology Advances, vol. 35, no. 4, pp. 450-457, 2017.

[12] C. Lewis, M. Jackson, K. Klesh, and M. Poliner, "Medical foods and US regulations," in Developing New Functional Food and Nutraceutical Products, pp. 407-416, Elsevier, Amsterdam, Netherlands, 2017.

[13] S. R. Bajaj and R. S. Singhal, "Degradation kinetics of vitamin $\mathrm{B}_{12}$ in model systems of different $\mathrm{pH}$ and extrapolation to carrot and lime juices," Journal of Food Engineering, vol. 272, Article ID 109800, 2020.

[14] M. Barr, S. Robert Kohn, and L. F. Tice, "The effect of various sugars and polyols on the stability of vitamin $\mathrm{B}_{12} * *$ Department of pharmacy, philadelphia college of pharmacy and science," Journal of the American Pharmaceutical Association, vol. 46, no. 11, pp. 650-652, 1957.

[15] P. Berry Ottaway, "Stability of vitamins during food processing and storage," in Chemical Deterioration and Physical Instability of Food and Beverages, pp. 539-560, Elsevier, Amsterdam, Netherlands, 2010.

[16] A. H. Lie, M. V. Chandra-Hioe, and J. Arcot, "Sorbitol enhances the physicochemical stability of $\mathrm{B}_{12}$ vitamers," International Journal for Vitamin and Nutrition Research, vol. 90, 2019.

[17] P. J. Stover, "Vitamin $B_{12}$ and older adults," Current Opinion in Clinical Nutrition and Metabolic Care, vol. 13, no. 1, pp. 24-27, 2010.

[18] AOAC, Appendix K: Guidelines for Dietary Supplements and Botanicals-Part I AOAC Guidelines for Single-Laboratory Validation of Chemical Methods for Dietary Supplements and Botanicals, Official Method of Analysis of AOAC International, Rockville, MD, USA, 2013.

[19] ICH, ICH Q2/R1 Validation of Analytical Procedures: Text and Methodology, International Conference on Harmonisation, Geneva, Switzerland, 2005.

[20] T. De Beer, M. Otto, B. Pretoruis, and H. C. Schönfeldt, "Monitoring the quality of honey: South African case study," Food Chemistry, vol. 343, Article ID 128527, 2021.

[21] M. Kumar and P. M. Kozlowski, "Electronic and structural properties of $\mathrm{Cob}(\mathrm{I})$ alamin: ramifications for $\mathrm{B}_{12}$-dependent processes," Coordination Chemistry Reviews, vol. 333, pp. 71-81, 2017.

[22] G. N. van Gorkom, E. L. Lookermans, C. H. Van Elssen, and G. M. Bos, "The effect of vitamin C (ascorbic acid) in the treatment of patients with cancer: a systematic review," Nutrients, vol. 11, no. 5, Article ID 977, 2019.

[23] H. Malmir, S. Shab-Bidar, and K. Djafarian, "Vitamin C intake in relation to bone mineral density and risk of hip fracture and osteoporosis: a systematic review and metaanalysis of observational studies," British Journal of Nutrition, vol. 119, no. 8, pp. 847-858, 2018.

[24] FDA, food additive status list, https://www.fda.gov/food/ food-additives-petitions/food-additive-status-list.

[25] T. Asadi, A. Azizi, J.-c. Lee, and M. Jahani, "Leaching of zinc from a lead-zinc flotation tailing sample using ferric sulphate and sulfuric acid media," Journal of Environmental Chemical Engineering, vol. 5, no. 5, pp. 4769-4775, 2017. 
[26] X. Zhang, X. Gu, S. Lu et al., "Application of ascorbic acid to enhance trichloroethene degradation by $\mathrm{Fe}(\mathrm{III})$-activated calcium peroxide," Chemical Engineering Journal, vol. 325, pp. 188-198, 2017.

[27] J. C. Deutsch, "Dehydroascorbic acid," Journal of Chromatography A, vol. 881, no. 1-2, pp. 299-307, 2000.

[28] FDA, frequently asked questions for industryon nutrition facts labeling requirements, https://www.fda.gov/media/ 99069/download.

[29] H. Pham, L. K. Phillips, and K. L. Jones, "Acute effects of nutritive and non-nutritive sweeteners on postprandial blood pressure," Nutrients, vol. 11, no. 8, Article ID 1717, 2019.

[30] C. I. Chukwuma and M. S. Islam, "Sorbitol increases muscle glucose uptake ex vivo and inhibits intestinal glucose absorption ex vivo and in normal and type 2 diabetic rats," Applied Physiology Nutrition and Metabolism, vol. 42, no. 4, pp. 377-383, 2017.

[31] W. Zhang, J. Chen, Q. Chen, H. Wu, and W. Mu, "Sugar alcohols derived from lactose: lactitol, galactitol, and sorbitol," Applied Microbiology and Biotechnology, vol. 104, no. 22, pp. $9487-9495,2020$. 